\title{
Literature Review of Executive Compensation Gap and Company Performance
}

\author{
Jie Gao \\ Department Management School, Jinan University, Guangzhou, China \\ Email: 13760818471@163.com
}

How to cite this paper: Gao, J. (2019) Literature Review of Executive Compensation Gap and Company Performance. American Journal of Industrial and Business Management, 9, 109-123. https://doi.org/10.4236/ajibm.2019.91009

Received: December 17, 2018

Accepted: January 13, 2019

Published: January 16, 2019

Copyright $\odot 2019$ by author (s) and Scientific Research Publishing Inc. This work is licensed under the Creative Commons Attribution International License (CC BY 4.0).

http://creativecommons.org/licenses/by/4.0/

\begin{abstract}
This paper mainly sorts out and summarizes literatures on executive compensation gap and enterprise performance, and puts forward the direction of further exploration. Firstly, this paper sorts out relevant literature from three perspectives: the relationship between executive compensation and corporate performance, internal compensation gap and corporate performance, and external compensation gap and corporate performance. Secondly, this paper reviews the research on executive compensation gap and enterprise performance. Finally, this paper proposes the future research direction of executive compensation gap and enterprise performance.
\end{abstract}

\section{Keywords}

Executive Compensation Gap, Company Performance

\section{Introduction}

Upper Echelon theory argues that with the fierce enterprise competition in the whole world, now executive members' working attitude and level largely determines the life of the enterprise. In order to attract and retain outstanding members of the executive and inspire them to achieve the great strategic goal of the enterprise, a key governance mechanism is needed (Hambrick, Altmann, Oswald, Meinz, Gobet and Campitelli, 2014) [1]. Executive pay gap is an important aspect of executive compensation research. In 2008, the event of "Sky-high executive compensation" of PING AN INSURANCE (GROUP) COMPANY triggers the social public's doubts on worse executive pay, even it triggers government to make regulations to limit excessive executive compensation of listed corporates. To sum up, the core of public questioning lies in whether the executive compensation matches the company performance. This paper starts from the internal and external compensation gap, then summarizes the relationship 
between the executive compensation gap and the company performance according to the previous literature, and finally puts forward the future prospect.

There are two contributions in this paper: First, this paper mainly sorts out and summarizes literatures on executive compensation gap and enterprise performance, and puts forward the direction of further exploration, which make the topic more clear and are useful for the future study. Second, this paper puts forward the original opinion from the perspective of research angle and research objects, and puts forward the suggestions for the actual mechanical process.

\section{Data and Methodology}

This paper adopts the method of literature review to sorts out and summarizes literatures on executive compensation gap and enterprise performance, and puts forward the direction of further exploration.

\section{Internal and External Salary Gap of Senior Executives and Company Performance}

\subsection{The Relationship between Executive Compensation and Enterprise Performance}

Executive compensation gap, also known as the distribution of executive compensation, is mainly manifested in two basic characteristics: the internal compensation gap within the executive team and the executive-employee compensation gap. Among them, the salary gap within the senior executive team refers to the difference in the salary amount between the CEO and other senior executive members, which indicates the difference in the salary that senior executives can get before and after promotion, and also reflects the effectiveness of the incentive mechanism for senior executives' earnings and promotion (Siegel and Hambrick, 2005; Lu, 2007) [2] [3]. Executive-employee salary gap refers to the absolute or relative difference between the average salary level of the entire executive team and the average salary level of ordinary employees. Executive pay gap is a double-edged sword, on the one hand, it can be used to form a strategic consensus and key strategy means to realize strategic landing, in order to promote the business enterprise inside members to compete against each other, mutual supervision of the motivation, the strengthening of the shareholders, the board of directors, executives and ordinary workers goals between the parties with risks, so as to improve corporate performance; On the other hand, It can also lead to unexpected negative consequences, including reducing the willingness to take risks, conniving at fraud in financial reports, triggering excessive earnings management, leading to contradictions among various groups within the enterprise and low employee satisfaction, and ultimately hindering the performance of the company.

Executive compensation gap and enterprise performance are complementary to each other. On the one hand, corporate performance can reflect the efforts of executives to some extent, so it is reasonable to determine executive compensa- 
tion based on corporate performance. On the other hand, executive compensation gap plays a very important role in the performance of enterprises. Establishing an excellent mechanism to attract and retain the incentive mechanism of senior executives who play a key role in the survival and development of enterprises is directly related to the performance of enterprises.

According to the optimal contract theory, determining executive compensation based on corporate performance can tie the interests of executives and shareholders together and reduce agency costs. At this time, corporate performance is an exogenous variable and a main factor determining executive compensation. However, motivated executives will further affect the performance of enterprises, so the performance of enterprises is also endogenous. How effective the incentive effect of executive compensation is and whether it has an incentive effect of improving corporate performance is an important criterion to test whether the executive compensation contract is effective. Zhou, Yang and Li (2010) [4] found that executive compensation was significantly positively correlated with company performance. Yang and Huang (2010) [5] found that senior executives who are motivated by salary can have after-effect on enterprise performance, that is, improve the performance of the enterprise in the next phase. These studies show that executive compensation incentive is conducive to improving corporate performance, but whether executive compensation incentive is the best incentive method is also worth studying. O'Connor and Rafferty (2010) [6] found that though the monetary compensation of corporate executives could improve returns, it could not maximize the value of shareholders. Jensen and Murphy (1990) [7] earlier proposed to use the regression method to study the relationship between executive monetary compensation and accounting performance, which is, the sensitivity of compensation performance. A large number of studies (Sloan, 1993; Baber, Kang and Kumar, 1999) [8] [9] showed that there is sensitivity between executive compensation and corporate performance, that is, corporate performance is an important factor determining executive compensation. These research results support the optimal contract theory.

\subsection{Internal Salary Gap and Company Performance}

Theoretical analysis on the impact of the internal gap in executive compensation on corporate performance can be summarized into the following two categories: first, championship theory supports widening the gap in executive compensation based on the economic view; Second, based on the behavioral view, it is opposed that the salary gap is too large based on the equity theory.

Tournament theory holds that the salary increase associated with a given promotion will affect the enthusiasm of employees who are below the work level. As long as the outcome of the promotion is unclear, employees have an incentive to work hard to get it. Therefore, the theory advocates that enterprises motivate employees through promotion.

Jensen and Meckling (1976) [10] argue that the salary and promotion of an 
enterprise can exert a strong incentive on agents' efforts, and reduce their lazy and free-riding behaviors at the same time. This is also the prototype of the original championship theory. Lazear and Rosen (1981) [11] that increase the salary gap can improve attitude and create performance. Rosen (1985) [12] studied principal-agent relationship with the method of game theory and conducted a direct study on the salary gap. He believed that the motivation for the senior management team to continue to move forward was that with the improvement of the administrative level, the salary level and the salary gap between adjacent levels increased. Lambert, Lanen and Larcker (1989) [13] found that with the improvement of the ranking level of senior management, the pay gap between CEO and other executives was the most obvious, and there was a positive correlation between the gap of executive compensation and corporate performance, which verified the tournament theory. Main, O'Reilly III and Wade (1993) [14] found that with the increase in the number of competitors, the chance of promotion would be reduced. Therefore, the salary gap between the $\mathrm{CEO}$ and the secondary manager should be increased to maintain a strong incentive effect. Once again, tournament theory was verified and the conclusion of behavioral theory was questioned. Henderson and Fredrickson (1996) [15] took American companies as samples and found that tournament theory was correlated with CEO's salary gap and could better predict the salary gap within the executive team. Using the data of state-owned enterprises, Liu and Sun (2010) [16] found that the internal salary gap between senior executives and employees was positively correlated with enterprise performance, and they also believed that the salary gap released the enthusiasm of senior executives and improved enterprise performance. Eriksson (1999) [17] found that the gap between executive compensation and business performance was significantly positively correlated. In addition, Zhao and Wang (2016) [18] found that except for some financial companies, the executive compensation of most listed central enterprises is not high. The salary gap between senior executives and employees has a positive incentive effect on enterprise performance to a certain extent. It accords with the championship theory which is popular in academic circles.

Some scholars support behavioral theory, which also known as social comparison theory. Social comparison theory holds that each individual uses others as the yardstick of comparison to conduct self-evaluation in the absence of objectivity. Everyone's perception of his or her own salary is based on comparison with others. They believe that a large salary gap cannot bring about a positive impact on the enterprise, but is more likely to give employees a sense of exploitation and injustice, reduce the enthusiasm of employees, and thus affect the performance of the enterprise. A small salary gap can generate continuous cohesion and improve employee satisfaction, thus improving enterprise performance. At the same time, too large salary gap is easy to breed employee dissatisfaction, and then have a negative impact on enterprise performance. O'Reilly III, Main and Crystal (1988) [19] analyzed the salary of 105 top executives of fortune 500 
companies and found that the salary gap within the executive team was weakly correlated with the company's performance. Akerlof and Yellen (1990) [20] replaced the company's performance indicators with good product quality, and the results showed that the wage level of different classes was significantly positively correlated with product quality. Siegel and Hambrick (1996) [21] and Siegel and Hambrick (2005) [2] have found that narrowing the salary gap can improve the degree of cooperation between employees, which is conducive to improving corporate performance and supporting behavioral theory. Zhang (2007) [22] and Lu (2007) [3] conducted an empirical study on the data of listed companies, and the results showed that the internal compensation gap of senior executives was negatively correlated with corporate performance. Zhang (2008) [23] found that the incentive effect of salary gap is lagging behind, studied the relationship between internal salary gap and future performance of enterprises, and found that the two are in a negative relationship. Wu (2011) [24] found a negative correlation between executive compensation and enterprise performance from the perspective of promotion mechanism. This negative relationship is more obvious in non-internal competition than in pure internal competition. Lu (2007) [3], Zhang (2008) [23] found that there was a significant negative correlation between salary gap and enterprise performance.

Different from the above conclusions, some literature studies have found that there is not a simple linear relationship between salary gap and enterprise performance, but an inverted U-shaped relationship. Lazear and Rosen (1981) [11] studied from the perspective of salary gap between senior executives and employees and found that there was still an inverted U-shaped relationship between salary gap and enterprise performance.

The above two theories also have some intermediate effects. Shaw (2012) [25] found that there is a strong formal individual incentive and independence in the work, and the larger the salary gap, the better the work performance. On the contrary, for jobs that lack mutual independence and formal individual incentives, the smaller the salary gap, the better the performance. Irlenbusch and $\mathrm{Ru}$ chala (2008) [26] conducted a further study on it and found that only when the relative remuneration was absolutely large, the higher the effort of employees, the less obvious the effect of too high or too low motivation on employees and the negative effect on the team. Domestic scholars have reached similar conclusions, with the deepening of the research perspective is also expanding. Lu (2009) [27] found that behavioral theory and tournament theory are actually complementary from the perspective of endogeneity. After controlling the endogeneity of the pay gap, the pay gap has an inverted $u$-shaped relationship with the company's performance. Chen and Zhang (2011) [28] added "destructive" factors into the competition model to study the influence of salary gap on enterprise performance, and found that they presented an inverted U-shaped relationship. Lv (2014) [29] added the influence of corporate personality differences on them and came to the same conclusion. Lu (2010) [30] looked at the rela- 
tionship between the two from the perspective of CEO source and found that the salary gap was conducive to the improvement of performance when the CEO was just replaced, while the widening of the salary gap was not conducive to the performance of the enterprise when the CEO was succeeded from the outside and the CEO held two concurrent posts. Based on the perspective of enterprise life cycle, Wang (2013) [31] found that tournament theory is more applicable to explain enterprises in the growth and maturity stages, while behavioral theory is applicable to the decline phase of enterprises. In addition, some scholars have studied the relationship between salary gap, investment efficiency and information disclosure. Liu and Feng (2015) [32] found that a large salary gap can promote enterprises to expand the scale of investment and improve the investment level and business performance of enterprises. Wang, Xiang and Yin (2015) [33], Wang and Xiang (2015) [34] found that the salary gap had incentive effect on the company's performance prediction behavior within a certain limit, and had negative incentive effect if it exceeded a certain limit. Yang and Wang (2014) [35], Zhang and Ma (2014) [36] found that the greater the salary gap, the higher the degree of earnings management, and this relationship is affected by the degree of ownership concentration and the nature of property rights.

\subsection{External Salary Gap and Company Performance}

Executive incentive usually includes two forms: explicit incentive and implicit incentive. The former mainly refers to monetary compensation incentive, which is stipulated in a clear contract form and can be further divided into salary contract, bonus plan, equity plan and option contract.

Implicit incentive is either lack of clear contract, or just a rule of principle, the common form of on-the-job consumption, insider trading income, political promotion and so on. The external salary gap corresponds to the internal salary gap. As an important monetary salary system design, it reflects certain social distribution characteristics and is an important explicit incentive form for senior executives. Scholars at home and abroad have conducted in-depth research on the phenomenon of external salary gap incentive and obtained rich research results. Studies such as Bizjak, Lemmon and Naveen (2008) [37], Faulkender and Yang (2010) [38] show that external salary gap has a positive value incentive effect, which can promote the improvement of economic benefits and corporate value.

Faulkender and Yang (2010) [38] found that when executive pay is low, neither on the executive incentive effect, nor on the loss of competitiveness in the talent market, the company general executive compensation will be determined in the industry benchmark compensation levels, therefore further enhance the level of industry benchmark compensation. And industry benchmark salary level of ascension will bring a new round of pay growth, thus forming a "Whoopi lake effect". Other scholars have also conducted in-depth research on the incentive effect of external salary gap. Wu, Lin and Wang (2010) [39] found that there was 
a positive correlation between positive excess compensation and performance of non-state-owned enterprises, while there was no significant correlation between negative excess compensation and performance. Jiang (2010) [40] showed that the industry average salary level is an important factor affecting the company's executive compensation, and the company often takes the industry average salary level as the benchmark salary, so that the company's executive compensation is equal to or higher than the benchmark salary, so as to generate corresponding incentive effect on the executives. Luo, Rang and Li (2012) [41] believe that the external salary gap is positively correlated with the company's performance, and that the external salary gap can promote the improvement of the company's value.

The above literatures show that external salary gap has value incentive effect, but does it show a incentive effect? According to Zou and Liu (2012) [42], when the demand for compensation reaches a saturation state, the marginal utility of executives in a dominant position is close to zero or even negative. The empirical test results of Shi and Yang (2013) [43] show that the internal and external salary gap of the senior management team has an inverted U-shaped relationship with the company's future performance. Qi and Zou (2014) [44] showed that the external equity of executive compensation significantly affects the performance of enterprises, and there is a range effect, which leads to the opportunity cost of fair distribution. Therefore, there should be a non-linear relationship between external salary gap and company value: within a certain limit, external salary gap has incentive effect and has a positive impact on company value; Beyond a certain limit, the external salary gap not only has no incentive effect, but also brings negative impact on the company's operation. The external salary gap has anti-incentive effect.

Wang and Xiang (2015) [34] study found that the external influence on the behavior of earnings forecast basically pay gap is inverted " $U$ " shaped relationship: inside certain limits has incentive effect on firm performance forecast behavior, with the increase of external compensation gap, increasing the quality of the earnings forecast information, timeliness, improved its decision usefulness, embodied in executive motive; Beyond a certain limit, there is a negative incentive effect. As the external salary gap increases, the quality of performance prediction information decreases, timeliness decreases, and tendency tends to be conservative. There is no evidence that executive power affects the effect of external salary gap on the behavior of corporate performance prediction. Further research shows that with the increase of on-the-job consumption, the influence of on-the-job consumption on the company's performance prediction behavior is basically inverted u-shaped. From the perspective of property rights, Li, Qin and $\mathrm{Hu}$ (2014) [45] found that the formulation of executive compensation in China was greatly affected by the growth of industry compensation, thus weakening the effectiveness of external compensation gap incentive. The greater the executive power of state-owned enterprises is, the more their compensation in- 
creases in that year. The executive power also weakens the incentive effect of external salary gap.

\section{Research Review on Executive Compensation Gap and Corporate Performance}

In conclusion, executive pay gap in this field and business performance research to present the following characteristics: 1) The research object, from the sample area in the United States, in Europe, to developing countries, in China also gradually to the addition of Chinese characteristics such as property right nature of the research, and international comparisons are emerging. 2) In terms of research methods, theoretical research and empirical research go hand in hand. At present, empirical research is dominant, and empirical research has gone from simple at the beginning to complex now, more detailed and more effective. Firstly, variables of internal and external salary gap are more detailed and diversified. Second, control variables and regulatory variables are more sophisticated, more evidence-based and more systematic. Thirdly, the application of data processing methods includes not only simple correlation analysis, variance analysis and linear regression analysis, but also more complex structural equation models that allow measurement errors and deal with the covariance between variables, as well as more sophisticated simultaneous equations models that control the endogeneity of variables. 3) On the research results of the internal pay gap, although there is debate tournament theory and behavior theory, the academic circles pay gap between the direct and the indirect influence on enterprise performance has reached a preliminary agreement, only on the specific impact continues to explore, and has the theoretical and practical value are given a variety of competing explanations for the follow-up study. For some scholars, no matter they find that there is a positive correlation between salary gap and enterprise performance (Eriksson, 1999; Mahy, Rycx and Volral, 2011; Li and $\mathrm{Hu}$, 2012; Gong, 2015; Zhao and Wang, 2016) [17] [18] [46] [47] [48], negative correlation (Zhang, 2007; Lu, 2007; Wu, 2011) [3] [22] [24] or inverted U-shaped linear relation (Lazear and Rosen, 1981; Zhang and Yang, 2015; Hao, 2016) [11] [49] [50], and for the external salary gap, its incentive effect has also been recognized by everyone, and most people believe that it has the characteristics of inverted $\mathrm{u}$-shaped linear relationship. To prove the different linear relationship, the possible research sample selection method, variable selection, whether companies are mature and empirical methods, different enterprise characteristics, such as a more important reason is that both the research in some degree the effect will be seen as "absolute effect", trying to find out the internal or external salary gap and the relationship between the universality and absoluteness of enterprise performance, and that this does not change due to objective factors, and, in fact, the relationship itself is very complicated. In fact, in reality gap between internal and external compensation and the relationship of the corporate performance is affected by various factors, coupled with a long theoretical research 
conclusion let we have reason to guess, the diversity of internal and external compensation gap between corporate performance and not absolute effect, the relationship may be of contingency, its existence, strength and direction are the regulation of some key variables. The existence level and state of other factors have a deep impact on the relationship between them. In view of this, the "contingency effect" perspective was introduced to study the relationship between the two, and specific situational adjustment variables were selected and combined to further the study and explore the relationship between internal and external salary gap and enterprise performance from various influencing factors.

\section{Research Prospect of Executive Compensation Gap and Enterprise Performance}

To sum up, there are three main research trends in this field: 1) More emphasis on vertical deepening development. With the gradual maturity of the research, the research topic selection is more detailed, the research context is more specific, the research method is more diversified, the research content is deepening, the variable measurement is more accurate, and the explanation of the new gap between senior executives and enterprise performance is more diversified. 2) More emphasis on comparative studies. Driven by the trend of vertical deepening, comparative research has been increasingly applied in this field, in order to better understand the essential characteristics of the relationship between executive compensation gap and enterprise performance and to obtain new findings. More scholars began to explore the differences and similarities of executive compensation gap and the role of corporate relationship in different countries, industries, regions and ownership enterprises from the perspective of comparative research, as well as the differences and similarities of executive compensation gap and corporate relationship under different life cycle backgrounds. 3) More emphasis on contingency perspective. It has been the latest trend of research in this field to admit that the gap between executive compensation and corporate performance is a "contingency effect" rather than an "absolute effect". Therefore, more and more scholars are interested in exploring the key contingency factors that can influence the internal relationship between executive compensation gap and enterprise performance based on the contingency perspective Element. Based on the above cognition, we expect that China's research in this field should (and will) make great progress in the following aspects in the future:

First of all, in order to comply with the trend of deepening the longitudinal development, future research should: 1) In terms of data collection methods, field survey data should be used to promote the in-depth development of the research. Existing studies only consider the result fairness of salary distribution but ignore the procedural fairness. In fact, the compensation decision-making and payment process, as well as how to explain the compensation system and compensation status quo to senior executives, will have an important impact on 
their attitude and behavior, thus affecting the formation of enterprise performance. Obviously, these data are not available in the public data of listed companies in China. Unfortunately, at present, most domestic researches are empirical data sources of public information of listed companies, so detailed data related to the fairness of executive compensation distribution process are not available, which weakens the accuracy and effectiveness of the research results. In view of this, future research should not only carry out empirical research based on the second-hand data published by listed companies, but also conduct in-depth field investigation to obtain specific and in-depth primary data and promote the in-depth development of research. 2) In the design of variable measurement, further strengthen the combination of objective indirect measurement and subjective direct measurement to promote the in-depth development of research. Pay gap measurement, for example, in the listed company to the public in traditional research objective data measurement of executive pay is only part of the "ought to be" static power, and in a larger extent, belongs to the internal pay gap, as executives are also affected by external compensation gap, the enterprise is based on the actual effect in the influence of internal and external compensation gap together, so in the past with objective data to measure effectiveness of listed companies. Obviously, it is necessary to supplement it with direct sensory measurement in order to more accurately reflect the characteristics of the pay gap. Therefore, the future research to executive pay gap, and the corporate performance research variables using a variety of measurement methods, using a variety of measurement to test the robustness of the empirical model, and stratified random sampling method is used to select the large capacity sample, improve the estimation precision, reduce the sampling error, ensure that research conclusion robustness, strengthening the credibility of research conclusion, expanding the scope of the research conclusion. 3) In terms of data analysis methods, guided by scientific cross-level research design idea, multi-level data analysis method is adopted to push the research to a deeper development. The existing researches mostly study the executive compensation gap at a single level, and the empirical model design also lacks the consideration of cross-level issues. In fact, the research on this issue involves at least the variables of the individual level and the organizational level, and has the characteristics of the individual level sex, the performance consequences of executive pay gap, both affect individual performance and enterprise performance. Therefore, it is likely that there will be a cross-level fallacy in previous studies. Future study should across the level of scientific research design, such as the macro-micro level connection of classical "bath" model was studied by means of hierarchical design, integrated application of analysis (WABA) between groups within the group, and hierarchical linear model (HLM) and cross level computation analysis (CLOP) multidimensional data analysis methods, such as, in order to avoid errors across levels of cesarean.

Secondly, in order to comply with the trend of emphasizing comparative re- 
search, future research should: 1) In terms of research objects, strengthen the comparative study of the impact of the salary gap between the newly appointed $\mathrm{CEO}$ and the senior CEO on enterprise performance. Current research mostly ignores the differences between new CEOs and senior CEOs. Existing literature study is essentially based on the root of the "CEO self-interest" hypothesis, the CEO may be suitable for senior, but based on the following two reasons, CEO is not suitable to be appointed for the first time: from the objective environment, CEO to be appointed in the "spotlight", the board of directors, shareholders and the public and so on various stakeholder groups have enough incentive pay close attention to its power In operation, all kinds of formal communication and supervision mechanism arrangements such as information disclosure, decision-making consultation, reporting and explanation for decisions made by first-term CEO will be more strictly implemented, so that first-term CEO will face greater supervision intensity and anger cost. Objectively, his behavior space and power capacity are obviously different from those of senior CEO. From subjective intention, compared with senior ceos, to be appointed the current CEO group have higher professional quality, more full of enthusiasm and professional ideal, more focused on their future career prospects rather than short-term interests in order to more long-term perspective, and with the enterprise has not left over from history "should not have to" various interest disputes, have stronger completes the subjective desire of enterprises, the behavior way, obviously different from senior chief executive power. In other words, the starting point of a new CEO's basic decision-making is more about profit than self-interest. Therefore, the incentive effect of executives in different periods has a direct impact on enterprise performance. 2) A comparative study should be conducted not only on the manipulation effect of executive compensation gap of managers' autonomy in different countries in the world, but also on the executive compensation gap and enterprise performance in different provinces in China.

Finally, in order to comply with the trend of strengthening the "contingency" perspective, future studies will focus on finding the key contingency factors among many possible factors, and conduct in-depth comparative studies on the adjustment effect of these key contingency factors on the relationship between manager autonomy and executive compensation gap. Existing research is very disagreeable to the relations, the difference in variable metric method and sample selection such as different empirical methods, and the difference in the effect seen as "absolute effect", trying to find out the gap of executive compensation and corporate performance. The relationship between universality and absoluteness is not due to objective factors change.

Under the guidance of this view, although the academic community has reached a preliminary consensus on the relationship between executive compensation gap and enterprise performance, there is no consensus on the strength and direction, and the explanation of the occurrence and evolution mechanism of the manipulation effect is not effective enough. Therefore, the research in this 
field needs to be further deepened. In fact, the diversity of CEO's attitude and preference towards executive compensation gap in reality, together with the diversity of theoretical research conclusions for a long time, makes it reasonable to guess that executive compensation gap and enterprise performance are not absolute effects, and the relationship between them may be. Because of this, the introduction of the "contingency effect" point of view to study the relations of the two, selecting and combining with the specific situationally adjusting variable, the research into the deep, to understand the manager autonomy mechanism on executive pay gap control effect, and the existing research conclusion very difference, and the decision making process of executive pay gap in each related interest groups provide effective theoretical guidance is of great significance. At present, foreign corporate governance structure factors, such as the proportion of state-owned shares, the degree of ownership concentration, the proportion of institutional investors holding shares, the proportion of independent directors, the functional positioning of the board of directors, etc. And the characteristics of enterprise operation factors, such as knowledge cooperation needs, strategic types, cultural atmosphere, interpersonal trust, etc. In comparison, domestic scholars still lack significant results from the perspective of "contingency effect". How the key contingency factors represented by the knowledge cooperation needs of the executive team affect the relationship between the executive pay gap and enterprise performance needs to be discussed in depth on the premise of national conditions.

\section{Conflicts of Interest}

The author declares no conflicts of interest regarding the publication of this paper.

\section{References}

[1] Hambrick, D.Z., Altmann, E.M., Oswald, F.L., Meinz, E.J., Gobet, F. and Campitelli, G. (2014) Accounting for Expert Performance: The Devil Is in the Details. Intelligence, 45, 112-114. https://doi.org/10.1016/j.intell.2014.01.007

[2] Siegel, P.A. and Hambrick, D.C. (2005) Pay Disparities within Top Management Groups: Evidence of Harmful Effects on Performance of High-Technology Firms. Organization Science, 16, 259-274. https://doi.org/10.1287/orsc.1050.0128

[3] Lu, H. (2007) Salary Gap, Cooperation Demand and Diversification Strategy within the Senior Management Team. Journal of Management Science, 20, 30-37.

[4] Zhou, R., Yang, Z. and Li, L. (2010) Correlation between Management Incentives and Business Performance-A Comparison between State-Owned and Non-StateControlled Listed Companies. Accounting Research, No. 12, 69-75.

[5] Yang, Q. and Huang, T. (2010) Are There After-Effects of CEO Compensation Incentives in Chinese Listed Companies? Journal of Financial Research, No. 1, 166-185.

[6] O’Connor, M.L. and Rafferty, M. (2010) Incentive Effects of Executive Compensation and the Valuation of Firm Assets. Journal of Corporate Finance, 16, 431-442. https://doi.org/10.1016/j.jcorpfin.2010.04.001 
[7] Jensen, M.C. and Murphy, K.J. (1990) Performance Pay and Top-Management Incentives. Journal of Political Economy, 98, 225-264. https://doi.org/10.1086/261677

[8] Sloan, R.G. (1993) Accounting Earnings and Top Executive Compensation. Journal of Accounting and Economics, 16, 55-100.

https://doi.org/10.1016/0165-4101(93)90005-Z

[9] Baber, W.R., Kang, S.-H. and Kumar, K.R. (1999) The Explanatory Power of Earnings Levels vs. Earnings Changes in the Context of Executive Compensation. The Accounting Review, 74, 459-472. https://doi.org/10.2308/accr.1999.74.4.459

[10] Jensen, M.C. and Meckling, W.H. (1976) Theory of the Firm: Managerial Behavior, Agency Costs and Ownership Structure. Journal of Financial Economics, 3, 305-360. https://doi.org/10.1016/0304-405X(76)90026-X

[11] Lazear, E.P. and Rosen, S. (1981) Rank-Order Tournaments as Optimum Labor Contracts. Journal of Political Economy, 89, 841-864. https://doi.org/10.1086/261010

[12] Rosen, S. (1985) Prizes and Incentives in Elimination Tournaments. The American Economic Review, 76, 701-715.

[13] Lambert, R.A., Lanen, W.N. and Larcker, D.F. (1989) Executive Stock Option Plans and Corporate Dividend Policy. Journal of Financial and Quantitative Analysis, 24, 409-425. https://doi.org/10.2307/2330976

[14] Main, B.G., O’Reilly III, C.A. and Wade, J. (1993) Top Executive Pay: Tournament or Teamwork? Journal of Labor Economics, 11, 606-628.

https://doi.org/10.1086/298309

[15] Henderson, A.D. and Fredrickson, J.W. (1996) Information-Processing Demands as a Determinant of CEO Compensation. Academy of Management Journal, 39, 575-606.

[16] Liu, C. and Sun, L. (2010) Salary Gap and Enterprise Performance: Empirical Evidence from State-Owned Listed Companies. Nankai Management Review, 2, 30-39.

[17] Eriksson, T. (1999) Executive Compensation and Tournament Theory: Empirical Tests on Danish Data. Journal of Labor Economics, 17, 262-280.

https://doi.org/10.1086/209920

[18] O’Reilly III, C.A., Main, B.G. and Crystal, G.S. (1988) CEO Compensation as Tournament and Social Comparison: A Tale of Two Theories. Administrative Science Quarterly, 33, 257-274.

[19] Akerlof, G.A. and Yellen, J.L. (1990) The Fair Wage-Effort Hypothesis and Unemployment. The Quarterly Journal of Economics, 105, 255-283. https://doi.org/10.2307/2937787

[20] Siegel, P. and Hambrick, D. (1996) Business Strategy and the Social Psychology of Top Management Teams. Advances in Strategic Management, 13, 91-119.

[21] Zhang, Z. (2007) High-Level Management Team Collaboration Needs, Salary Gap and Enterprise Performance: The Perspective of Competition Theory. Nankai Management Review, 10, 4-11.

[22] Zhang, Z. (2008) Empirical Study on the Influence of Internal Salary Gap on the Future Performance of Organizations. Accounting Research, 9, 81-87.

[23] Wu, Q. (2011) Compensation Gap, Enterprise Performance and Promotion Mechanism-Re-Test of Executive Compensation Championship. World Economic Literature, 5, 94-105.

[24] Shaw, K.W. (2012) CEO Incentives and the Cost of Debt. Review of Quantitative Finance and Accounting, 38, 323-346. https://doi.org/10.1007/s11156-011-0230-7 
[25] Irlenbusch, B. and Ruchala, G.K. (2008) Relative Rewards within Team-Based Compensation. Labour Economics, 15, 141-167. https://doi.org/10.1016/j.labeco.2007.02.003

[26] Lu, H. (2009) Research on Executive Pay Gap and Company Performance from Endogenous Perspective. Soft Science, 23, 22-29.

[27] Chen, D. and Zhang, S. (2011) Empirical Analysis of Neighborhood Effect of Unemployment Rate in China. Journal of Population and Economy, 5, 36-39.

[28] Lv, J. (2014) Heterogeneous Enterprises, Salary Gap and Enterprise Performance. Research on Financial Problems, 1, 71-79.

[29] Lu, H. (2010) Research on Executive Pay Gap, CEO Internal Succession Opportunity and Company Performance-Empirical Analysis Based on Tournament Theory. South China Journal of Economics, No. 5, 23-32 + 10.

[30] Wang, C. (2013) Enterprise Life Cycle, Executive Compensation Gap and Enterprise Value. New Accounting, 1, 9-12.

[31] Liu, M. and Feng, L. (2015) Internal Executive Compensation Gap, Investment Behavior and Corporate Performance-A Case Study of a-Share Listed Manufacturing Enterprises in China. Journal of Scientific Decision, No. 10, 66-81.

[32] Wang, H., Xiang, X. and Yin, P. (2015) Executive Power, External Salary Gap and Corporate Performance Prediction Behavior-Based on Empirical Evidence of China's Securities Market. Journal of Huazhong University of Science and Technology (Social Science Edition), No. 6, 92-104.

[33] Wang, H. and Xiang, X. (2015) Executive Power, Internal Salary Gap and Corporate Performance Prediction Behavior-Based on Empirical Evidence of China's Securities Market. Investment Research, No. 10, 124-141.

[34] Yang, Z. and Wang, H. (2014) Internal Compensation Gap, Equity Concentration and Earnings Management Behavior-Based on the Comparative Analysis of Compensation within the Executive Team and between Executives and Employees. Accounting Research of China, No. 6, 57-65.

[35] Zhang, Z. and Ma, Y. (2014) Marketization Process, Salary Gap and Earnings Management Mode Selection. Journal of Shanxi University of Finance and Economics, No. 7, 91-104.

[36] Bizjak, J.M., Lemmon, M.L. and Naveen, L. (2008) Does the Use of Peer Groups Contribute to Higher Pay and Less Efficient Compensation? Journal of Financial Economics, 90, 152-168. https://doi.org/10.1016/j.jfineco.2007.08.007

[37] Faulkender, M. and Yang, J. (2010) Inside the Black Box: The Role and Composition of Compensation Peer Groups. Journal of Financial Economics, 96, 257-270. https://doi.org/10.1016/j.jfineco.2010.01.006

[38] Wu, L., Lin, J. and Wang, Y. (2010) Compensation External Equity, Equity Nature and Company Performance. Management of the World, No. 3, 117-126.

[39] Jiang, W. (2010) Industry Salary Benchmark and Manager Salary Growth-Based on Empirical Analysis of Listed Companies in China. Journal of Financial Research, No. 4, 144-159.

[40] Luo, R., Rang, D. and Li, H. (2012) Income Gap Analysis at the Social Level-Based on Research in the Power, Oil and Financial Sectors. Entrepreneur World: The Next Ten-Day Issue, No. 5, 19-19.

[41] Zou, Y. and Liu, C. (2012) Study on the Influence of Monopoly on Market Price and Social Equity. Theory and Practice of Finance and Economics, 33, 2-6.

[42] Shi, Y. and Yang, H. (2013) Empirical Study on the Influence of Internal and Ex- 
ternal Salary Gap on the Future Performance of the Company. Economic Survey, No. 1, 104-108.

[43] Qi, J. and Zou, Y. (2014) Empirical Study on the Incentive Effect of External Equity of Executive Compensation on Agent Behavior. Accounting Research Study, No. 3, 26-32.

[44] Li, W., Qin, Y. and Hu, Y. (2014) Does the External Pay Gap Motivate Executives-An Empirical Study Based on the Manager Market and Property Rights Nature of Chinese Listed Companies. Nankai Management Review, No. 4, 24-35.

[45] Mahy, B., Rycx, F. and Volral, M. (2011) Does Wage Dispersion Make All Firms Productive? Scottish Journal of Political Economy, 58, 455-489. https://doi.org/10.1111/j.1467-9485.2011.00555.x

[46] Li, W. and Hu, Y. (2012) Who Is Encouraged by the Salary Gap within Soes? Economic Research Journal, 12, 125-136.

[47] Gong, N. (2015) Empirical Analysis of Executive Compensation Gap, Performance Relationship between Controlling Shareholders and Private Listed Companies. Journal of Central University of Finance and Economics, No. 7, 64.

[48] Zhao, J. and Wang, Y. (2016) Analysis of Effects on Intra-Firm Compensation Gap to Enterprise Performance-Take Public Companies of Central Enterprises as an Example. Modern Management, 6, 35. https://doi.org/10.12677/MM.2016.62006

[49] Zhang, D. and Yang, X. (2015) Executive Compensation, Internal Gap and Commercial Bank Performance. Journal of Central University of Finance and Economics, 3, 62-71.

[50] Hao, D. (2016) Product Market Competition, Internal Salary Gap and Company Performance. Journal of East China Normal University (Philosophy and Social Science Edition), 1, 23. 